\title{
Effects of Endurance and Endurance Strength Training on Body Composition and Physical Capacity in Women with Abdominal Obesity
}

\author{
Damian Skrypnik $^{a} \quad$ Paweł Bogdański $^{b} \quad$ Edyta Mądry ${ }^{c}$ \\ Joanna Karolkiewicz ${ }^{d} \quad$ Marzena Ratajczak $^{d}$ Jakub Kryściak ${ }^{d}$ \\ Danuta Pupek-Musialik $^{a}$ Jarosław Walkowiak ${ }^{\mathrm{e}}$ \\ ${ }^{a}$ Department of Internal Medicine, Metabolic Disorders and Hypertension, University of \\ Medical Sciences, Poznań, Poland; ${ }^{b}$ Department of Education and Obesity Treatment and \\ Metabolic Disorders, University of Medical Sciences, Poznań, Poland; ' Department of \\ Physiology, University of Medical Sciences, Poznań, Poland; 'd Department of Physiology, \\ Biochemistry and Hygiene, University School of Physical Education, Poznań, Poland; \\ e Department of Pediatric Gastroenterology and Metabolic Diseases, University of Medical \\ Sciences, Poznań, Poland
}

\author{
Key Words \\ Obesity · Exercise $\cdot$ Body composition
}

\begin{abstract}
Aims: To compare the effects of endurance training with endurance strength training on the anthropometric, body composition, physical capacity, and circulatory parameters in obese women. Methods: 44 women with abdominal obesity were randomized into groups $A$ and $B$, and asked to perform endurance $(A)$ and endurance strength training (B) for 3 months, 3 times/week, for $60 \mathrm{~min}$. Dual-energy X-ray absorptiometry and Graded Exercise Test were performed before and after training. Results: Significant decreases in body mass, BMI, total body fat, total body fat mass, and waist and hip circumference were observed after both types of intervention. Marked increases in total body lean and total body fat-free mass were documented in group $B$. In both groups, significant increases in peak oxygen uptake, time to exhaustion, maximal work rate, and work rate at ventilatory threshold were accompanied by noticeably decreased resting heart rate, resting systolic blood pressure, and resting and exercise diastolic blood pressure. No significant differences were noticed between groups for the investigated parameters. Conclusion: Our findings demonstrate evidence for a favorable and comparable effect of 3-month endurance and endurance strength training on anthropometric parameters, body composition, physical capacity, and circulatory system function in women with abdominal obesity.
\end{abstract}


Skrypnik et al.: Effects of Endurance and Endurance Strength Training on Body

Composition and Physical Capacity in Women with Abdominal Obesity

\section{Introduction}

Obesity has been recognized by the World Health Organization as the most visible and, at the same time, the most ignored problem of public health worldwide [1]. The problem of obesity affects 500 million adults [2]. It has been demonstrated that a BMI exceeding 35 $\mathrm{kg} / \mathrm{m}^{2}$ at the age of 20 shortens life expectancy by 13 years [3]. People with a BMI in the $40-49.9 \mathrm{~kg} / \mathrm{m}^{2}$ range had an annual risk of death nearly twice as high as those with a BMI in the $22.5-24.9 \mathrm{~kg} / \mathrm{m}^{2}$ range [4]. It is estimated that in the USA alone obesity is the cause of more than 300,000 deaths per year [5]. The total annual medical cost of obesity treatment in the USA exceeds USD 140 billion, which represents $9.1 \%$ of annual medical costs [6]. The main causes of mortality in people with obesity are cardiovascular diseases (CVD), type-2 diabetes mellitus (DM2), and some cancers.

The American Heart Association recommends weight loss in obese patients to reduce the severity of cardiometabolic risk factors, such as metabolic syndrome, insulin resistance,DM2, hypertension, dyslipidemia, CVD, and inflammation [7]. Clinically significant weight loss ( $\geq 5 \%$ of the baseline body weight) is claimed to be an effective way of reducing CVD and DM2 risk factors, and should be the object of every plan of treatment [8]. Physical activity should be implemented in obesity therapy protocols, regardless of the baseline body weight or weight loss goals. Physical training is known to be associated with body weight loss and with reductions in cardiovascular, diabetic, and all-cause mortality, leading to an increase in life expectancy and countering the negative health impact of obesity $[9,10]$. It has been shown that aerobic endurance training in particular leads to numerous health benefits, and there is great evidence for its favorable influence on weight [11], glucose control [12], endothelial function [13], glomerular filtration rate (GFR) [14], lipoprotein particle size [15], and concentration of high-density lipoproteins [16] as well as for an overall improvement in quality of life [17]. Aerobic endurance training is the most recommended type of exercise in the treatment of obesity [18]. According to the European Clinical Practice Guidelines of the European Association for the Study of Obesity (EASO), aerobic endurance training of a moderate but gradually increasing intensity, adapted to the patients' health state and ability, should be undertaken on most days of week, for 30-60 min daily, by people of all ages [19]. Alternatively, the results of recent research indicate numerous potential advantages of strength training in the therapy of obesity, including increases in muscle strength, prevention of sarcopenia with ageing, preservation of bone mineral density, and reduction of body fat $[11,20]$. Such evidence of the benefits of the implementation of strength exercise in the treatment of obesity has initiated a discussion on the necessity of developing an optimal training program. The European Society of Hypertension and the European Society of Cardiology, in their 2013 guidelines for the management of arterial hypertension, recommend dynamic resistance training, though not isometric training, performed 2-3 days per week as a means to reduce blood pressure and improve metabolic parameters [21]. Strength exercises seem to be a neglected aspect of the recommendations concerning the treatment of obesity by exercise.

So far, there has been no convincing scientific evidence from well-planned trials with randomization, which might serve as a basis for revising the recommendations regarding physical activity in the treatment of obesity. This fact is complicated by data indicating that the response to physical activity is, in some aspects, dissimilar in men and women [22, 23]. It has been recently suggested that physical activity plans should be designed differently for each gender [23]. Therefore, a homogenous unisexual population of healthy obese women was enrolled into our study to estimate the impact of different training programs on some parameters related to obesity in this gender. 
The aim of this study was to compare the influence of short-term endurance training and short term endurance strength training on anthropometric parameters, body composition, physical capacity, and the circulatory system in healthy women with abdominal obesity.

\section{Material and Methods}

\section{Study Patients}

Informed consent was obtained from all subjects, and the study was approved by the Ethics Committee of Poznań University of Medical Sciences, registered as case no. 1077/12 with supplement (no. 753/13). The trial protocol has been approved by an ethical committee and thus meets the standards of the Declaration of Helsinki in its revised version of 1975 and its amendments of 1983, 1989, and 1996. From the 163 registered women with obesity screened at the outpatient clinic of the Department of Internal Medicine, Metabolic Disorders, and Hypertension, University of Medical Sciences, Poznań, Poland, a total of 44 women were enrolled.

The inclusion criteria were as follows i) written and informed consent of the subject for participation in the study; ii) age 18-65 years; iii) simple obesity (BMI $\left.\geq 30 \mathrm{~kg} / \mathrm{m}^{2}\right)$; iv) waist circumference $>80 \mathrm{~cm}$; v) content of body fat assessed by electrical bioimpedance $\geq 33 \%$; vi) stable body weight in the month prior to the trial (permissible deviation was $\pm 1 \mathrm{~kg}$ ).

The exclusion criteria were i) secondary form of obesity and/or secondary form of hypertension; ii) DM2; iii) history of coronary artery disease; iv) stroke (including transient ischemic attack); v) congestive heart failure; vi) clinically significant arrhythmias or conduction disorders; vii) malignancy; viii) history of use of any dietary supplements within 3 months before the study; ix) poorly controlled hypertension (mean systolic blood pressure (SBP) $>140 \mathrm{~mm} \mathrm{Hg}$ and/or mean diastolic blood pressure (DBP) $>90 \mathrm{~mm} \mathrm{Hg}$ ) during the month prior to the trial and/or necessity to modify antihypertensive treatment in the 3 months prior to the trial; $\mathrm{x}$ ) lipid disorders requiring the implementation of drug treatment in the 3 months prior to the trial or during the trial; xi) abnormal liver, kidney, or thyroid gland function; xii) clinically significant acute or chronic inflammatory process within the respiratory, digestive, or genitourinary tract, or in the oral cavity, pharynx, or paranasal sinuses, or connective tissue disease or arthritis; xiii) history of infection in the month prior to the study; xiv) nicotine, alcohol, or drug abuse; xv) pregnancy or childbirth at enrollment or in the 3 months prior to enrollment; xvi) current lactation or lactation in the 3 months prior to enrollment; xvii) and/ or any other condition that, in the opinion of the investigators, would make participation not in the best interest of the subject, or could prevent, limit, or confound the efficacy of the study. The occurrence of any of the above exclusion criteria during the trial resulted in immediate cessation of participation in the study.

\section{Study Design}

The study was designed as a prospective randomized trial. Subjects were randomized into 2 groups, A and B, using a randomization list. Both groups performed 3 months of physical training. Group A underwent endurance training, while group $B$ in parallel underwent endurance strength training of comparable exercise volume. Aside from the training, all subjects were instructed to maintain the physical activity and diet that they had been practicing. At the baseline, and after the 3 months of physical training, anthropometric and body composition measurements, physical capacity measurements, and circulatory system measurements were performed in both groups.

\section{Anthropometric and Body Composition Measurements}

\section{Anthropometric Parameters}

Anthropometric measurements were conducted with the subjects wearing light clothing and no shoes. Weight was measured to the nearest $0.1 \mathrm{~kg}$ and height to the nearest $0.5 \mathrm{~cm}$. BMI was calculated as weight divided by height squared $\left(\mathrm{kg} / \mathrm{m}^{2}\right)$. Obesity was defined as BMI $\geq 30 \mathrm{~kg} / \mathrm{m}^{2}$. Waist circumference $(\mathrm{cm})$ was measured at the level of the iliac crest at the end of normal expiration. Hip circumference was measured at 
Skrypnik et al.: Effects of Endurance and Endurance Strength Training on Body

Composition and Physical Capacity in Women with Abdominal Obesity

the maximum protuberance of the buttocks. Waist and hip circumferences were measured to the nearest 0.5 $\mathrm{cm}$. Waist-to-hip ratio (WHR) was calculated as waist circumference divided by hip circumference.

\section{Analysis of Bioimpedance}

Fat content was determined using analysis of bioimpedance with a Bodystat analyzer $\left(1500\right.$ MDD $^{\circledR}$; Bodystat Ltd, Isle of Man). The analysis was performed after a night's rest under metabolic laboratory conditions. The fat content was determined using analysis of bioimpedance only to verify the inclusion criteria, with fat content $\geq 33 \%$ including the subject to the study.

\section{Dual-Energy X-Ray Absorptiometry (DXA)}

Body composition analysis was assessed using DXA (GE Healthcare Lunar Prodigy Advance; GE Medical Systems, Milan, Italy). This method is considered the gold standard for body composition measurements in the case of obese individuals. The subjects were instructed not to make any intense physical effort in the 24 $\mathrm{h}$ prior to the examination. The subjects were given complete instructions on the examination procedure. They wore cotton T-shirt, shorts, and socks and lay on the DXA table supine and motionlessly during the testing procedure. They were instructed to remove all metal, rubber, and plastic objects that might affect the $\mathrm{X}$-ray beam. The procedure took approximately $15 \mathrm{~min}$. The DXA machine was reset each day according to the standard procedure to assure quality, and a spine and anthropomorphic phantom were scanned daily to the same end. The same well-trained laboratory technician positioned the subjects, performed the scans, and executed the analysis according to the operator's manual, using the standard analysis protocol. Total body fat mass (TBFat), total body lean mass (TBLean), and total body fat-free mass were determined using standard scan mode (in case of moderately obese subjects) or thick scan mode (in case of extremely obese subjects); the absorbed dose of radiation was $0.4 \mu \mathrm{Gy}$ and $0.8 \mu \mathrm{Gy}$, respectively. For statistical analysis, the change in TBFat was calculated as the baseline measurements minus the trial completion measurements; the change in TBLean was calculated as the trial completion measurements minus the baseline measurements. The intra- and inter-subject coefficients of variation (CV\% $=100 \times \mathrm{SD} / \mathrm{mean}$ ) ranged from 1 to $5 \%$. The coefficient of variation for bone mass measurements was $<1 \%$; on this instrument, the coefficients for 5 subjects scanned 6 times over a 9-month period were $2.2 \%$ for TBFat and $1.1 \%$ for TBLean.

\section{Physical Capacity Measurements}

To determine the subjects' physical capacity, a Graded Exercise Test (GXT) was performed on an electronically braked cycle ergometer (Kettler ${ }^{\circledR}$ DX1 Pro, Kettler, Ense, Germany). GXT is a reliable and widely used method of determining physical capacity. GXT began at a work rate of $25 \mathrm{~W}$ ( $60 \mathrm{rev} / \mathrm{min})$. The work rate was incremented by $25 \mathrm{~W}$ every 2 min until the subject could no longer maintain the required pedal cadence. Each test lasted 4-14.5 min, depending on age and aerobic fitness status. The exercise tests were conducted between 8:00 and 12:00 a.m. in an air-conditioned laboratory, $2 \mathrm{~h}$ after consuming a light breakfast. Expired gases, minute ventilations (Ve), and heart rate (HR) during GXT were monitored continuously with an automated system (Oxycon Mobile ${ }^{\circledR}$; Viasys Healthcare, Hoechberg, Germany). Oxygen intake $\left(\mathrm{VO}_{2}\right.$ ) and carbon dioxide output $\left(\mathrm{VCO}_{2}\right)$ was measured breath-by-breath and averaged over 15-second periods. Before each trial, the system was calibrated according to the manufacturer's instructions. The ambient conditions of temperature, humidity, and barometric pressure were recorded by the sensors. In a two-point volume calibration ( 0.2 and $2.0 \mathrm{l} / \mathrm{s})$, the flow values were measured automatically at the set measuring points. Gas analyzer calibration was performed using the standard gas mixture of $5 \% \mathrm{CO}_{2}$ and $16 \% \mathrm{O}_{2}$. Peak $\mathrm{VO}_{2}$ was defined as the highest 15 -second averaged $\mathrm{VO}_{2}$ obtained during the final exercise load on the test. HRpeak (bpm) was measured as the highest 15-second average value in the test. Time to exhaustion (TTE) and maximal work rate (WRmax) were also measured. To determine ventilatory threshold (VT), the V-slope method was administered using computerized regression analysis on the slopes of the $\mathrm{CO}_{2}$ output versus $\mathrm{O}_{2}$ uptake plot, which detects the beginning of the excess $\mathrm{CO}_{2}$ output generated from the buffering of $\mathrm{H}^{+}$. The method involves analyzing the behavior of $\mathrm{VCO}_{2}$ as a function of $\mathrm{VO}_{2}$ during GXT with a consequent increase in $\mathrm{VCO}_{2}$. This results in a transition in the relationship between $\mathrm{VCO}_{2}$ and $\mathrm{VO}_{2}$. The software supplied by Viasys Healthcare was used, supported with a visual inspection on the part of an experienced researcher. As a secondary method, the ventilatory equivalent method (VEQ method) was employed and the point at which the equivalent for oxygen $\left(\mathrm{VE} / \mathrm{VO}_{2}\right)$ increased without a concomitant rise in the equivalent for carbon dioxide $\left(\mathrm{VE} / \mathrm{VCO}_{2}\right)$ was detected. The VT was expressed as work rate $\left(\mathrm{WR}_{\mathrm{VT}}\right)$ and heart rate $\left(\mathrm{HR}_{\mathrm{VT}}\right)$. 


\section{Circulatory System Measurements}

Resting blood pressure was measured using a digital electronic tensiometer (model 705ITTM, Omron Corporation, Kyoto, Japan). Regular or large adult cuffs were used, depending on the patient's arm circumference. The measure was taken fasting in the morning hours, in a sitting position with the legs uncrossed and the back and arm supported. Resting HR was measured under the same conditions, using auscultation of the heart by stethoscope.

Exercise blood pressure was measured during a GXT using a digital electronic tensiometer (model 705IT). Regular or large adult cuffs were used, depending on patient's arm circumference. The measurement was taken during maximal work rate. Exercise HR was measured as the highest 15-second average value in the GXT.

\section{Intervention}

The 3-month intervention consisted of a physical exercise program, including 3 sessions of training per week (on Mondays, Wednesdays, and Fridays). A total of 36 training sessions were carried out for each group. Training was performed under the supervision of a qualified and certified fitness instructor, and under medical supervision, in a professional training room situated in Sport Club City Zen, Poznań. Group A underwent endurance training on cycle ergometers (Schwinn Evolution, Schwinn Bicycle Company, Boulder, CO, USA). Training sessions consisted of 5 min of warm-up (stretching exercises) at low intensity (50-60\% of maximum HR); 45 min of training at an intensity between 50 and $80 \%$ of maximum HR; 5 min of cycling without load, and $5 \mathrm{~min}$ of closing stretching and breathing exercises of low intensity. Group B underwent endurance strength training, which consisted of 5 min of warm-up (stretching exercises) of low intensity (50-60\% of maximum HR), a strength component, an endurance component, cycling without load, and closing exercises. The strength component involved $20 \mathrm{~min}$ of strength exercises with a neck barbell and a gymnastic ball. To allow muscle power to regenerate, the strength component was variable and repeated regularly every week. On Mondays, upper limb exercises were performed with a neck barbell; Wednesdays involved spine-stabilizing exercises, deep muscle-forming exercises, and balance-adjusting exercises with a gymnastic ball; on Fridays, lower limb exercises with a neck barbell were carried out. The exercises were repeated in series. The number of repetitions of each exercise in the series was dependent on the subjects' muscle strength and was equal to the number of repetitions performed correctly. The number of repetitions was systematically increased with the increase in subjects' muscle strength. Between the series of strength exercises, 10- to 15 -second regeneration pauses were taken, during which subjects performed isometric exercises. Directly after the strength exercises, the subjects underwent $25 \mathrm{~min}$ of endurance exercise on cycle ergometers (Schwinn Evolution) of intensity between 50 and 80\% of maximum HR, 5 min of cycling without load, and 5 min of closing stretching and breathing exercises of low intensity. HR during training was monitored with a Suunto Fitness Solution ${ }^{\circledR}$ device (Suunto, Vantaa, Finland). Both training programs were comparable in exercise volume and varied only in the nature of the effort.

\section{Dietary and Supplement Intake}

At baseline, every 14 days during the intervention, and upon completion of the trial, dietary intake was determined on the basis of dietary intake interviews. The amount of nutrients in the daily diet was processed and evaluated using a dietetics computer program. The intake of nutrients, total caloric intake, and caffeine consumption during the study were constant and comparable between the groups. Subjects were instructed to not use any dietary supplements.

\section{Statistical Analysis}

Data are presented as means \pm SD. All calculations and statistics were performed using STATISTICA 6.0 software (StatSoft, Inc. ${ }^{\circledR}$, Krakow, Poland). Comparisons between groups were performed using the MannWhitney U test. The Wilcoxon rank sum test was used to analyze the statistical significance between variables 
Table 1. Baseline characteristics of study groups

\begin{tabular}{llll}
\hline Variables & $\begin{array}{l}\text { Group A } \\
(\mathrm{n}=21)\end{array}$ & $\begin{array}{l}\text { Group B } \\
(\mathrm{n}=17)\end{array}$ & p value \\
\hline Age, years & $51.3 \pm 8.3$ & $48.2 \pm 11.2$ & $\mathrm{NS}$ \\
Body mass, kg & $91.7 \pm 11.8$ & $94.5 \pm 13.4$ & $\mathrm{NS}$ \\
BMI, kg/m & $35.2 \pm 3.9$ & $34.9 \pm 3.8$ & $\mathrm{NS}$ \\
Waist circumference, cm & $110.8 \pm 10.2$ & $111.6 \pm 11.3$ & $\mathrm{NS}$ \\
Hip circumference, cm & $115.0 \pm 8.0$ & $115.8 \pm 9.4$ & $\mathrm{NS}$ \\
WHR & $0.96 \pm 0.06$ & $0.96 \pm 0.07$ & $\mathrm{NS}$ \\
Resting HR, bpm & $79.7 \pm 14.1$ & $75.2 \pm 8.1$ & $\mathrm{NS}$ \\
Resting SBP, mm Hg & $138.1 \pm 11.9$ & $141.4 \pm 18.4$ & $\mathrm{NS}$ \\
Resting DBP, mm Hg & $83.2 \pm 10.9$ & $84.8 \pm 11.6$ & $\mathrm{NS}$ \\
Total body fat, \%fat & $47.5 \pm 4.0$ & $46.9 \pm 3.7$ & $\mathrm{NS}$ \\
Total body lean mass, g & $45,969.0 \pm 5,468.3$ & $47,843.9 \pm 6,280.4$ & $\mathrm{NS}$ \\
VO $_{2 \text { peak, }}$ ml/(kg $\times$ min) & $17.3 \pm 2.1$ & $18.3 \pm 3.3$ & $\mathrm{NS}$ \\
HR $_{\text {peak, }}$ bpm & $146.0 \pm 18.0$ & $154.6 \pm 23.3$ & $\mathrm{NS}$ \\
WR $_{\text {max }}$ W & $104.8 \pm 17.0$ & $113.2 \pm 23.6$ & $\mathrm{NS}$
\end{tabular}

NS = Not significant.

before and after the 3-month intervention. A p value of less than 0.05 was regarded as significant. It was calculated that a sample size of at least 15 subjects in each group would yield at least $80 \%$ power of detecting an intervention effect that was statistically significant at the $0.05 \alpha$ level.

\section{Results}

163 subjects were examined during the pre-randomization process. 119 were excluded from the trial due to poorly controlled hypertension ( 49 subjects), stroke ( 6 subjects), history of coronary artery disease (18 subjects), congestive heart failure (16 subjects), clinically significant inflammatory process within the respiratory tract (15 subjects), abnormal liver function ( 9 subjects), and abnormal kidney function ( 6 subjects). After screening, 44 subjects fulfilled all the inclusion criteria and had no exclusion criteria. They were randomized to two equal groups, $A$ and $B$, each consisting of 22 subjects. 1 subject from group $A$ and 5 from group $B$ were withdrawn from the trial following randomization, because of low attendance in intervention process $(<70 \%)$ ). 38 subjects completed the trial and underwent analysis -21 from group A and 17 from group B. The compliance ratio was $86.4 \%$. No significant changes in diet were recorded. There were no statistically significant differences between the two training groups prior to the study. Baseline characteristics of the groups are presented in table 1.

Compared with the baseline measurements, both interventions - endurance training as well as endurance strength training - resulted in significant decreases in body mass, BMI, waist circumference, and hip circumference. A comparison of the anthropometric parameters before and after the intervention is presented in table 2 .

Both types of intervention led to significant decreases in total body fat (\%fat) and TBFat. Significant increases in TBLean and total body fat-free mass were observed only in group B (table 3).

Compared with baseline measurements, both interventions - endurance training as well as endurance strength training - resulted in significant increase in $\mathrm{VO}_{2 \text { peak, }}$ WRmax, TTE, and WRVT. Also, a tendency for $\mathrm{HR}_{\mathrm{VT}}$ to increase was recorded in both groups, but was not significant. A comparison of the body's physical capacity (GXT) parameters before and after the intervention is presented in table 4 . 
Skrypnik et al.: Effects of Endurance and Endurance Strength Training on Body

Composition and Physical Capacity in Women with Abdominal Obesity

Table 2. Comparison of anthropometric parameters before and after the intervention in groups A and B

\begin{tabular}{|c|c|c|c|c|c|c|}
\hline Variables & $\begin{array}{l}\text { Group A before } \\
\text { intervention } \\
(\mathrm{n}=21)\end{array}$ & $\begin{array}{l}\text { Group A after } \\
\text { intervention } \\
(n=21)\end{array}$ & $\mathrm{p}$ value $\mathrm{a}^{\mathrm{a}}$ & $\begin{array}{l}\text { Group B before } \\
\text { intervention } \\
(n=17)\end{array}$ & $\begin{array}{l}\text { Group B after } \\
\text { intervention } \\
(n=17)\end{array}$ & $\mathrm{p}$ value \\
\hline Body mass, kg & $91.7 \pm 11.8$ & $89.5 \pm 11.8$ & $<0.001$ & $94.5 \pm 13.4$ & $91.8 \pm 13.7$ & 0.003 \\
\hline BMI, $\mathrm{kg} / \mathrm{m}^{2}$ & $35.2 \pm 3.9$ & $34.3 \pm 3.9$ & $<0.001$ & $34.9 \pm 3.8$ & $33.9 \pm 4.1$ & $<0.001$ \\
\hline Waist circumference, $\mathrm{cm}$ & $110.8 \pm 10.2$ & $105.5 \pm 11.1$ & $<0.001$ & $111.7 \pm 11.3$ & $104.0 \pm 10.5$ & $<0.001$ \\
\hline Hip circumference, $\mathrm{cm}$ & $115.0 \pm 8.0$ & $111.7 \pm 8.5$ & $<0.001$ & $115.8 \pm 9.4$ & $112.4 \pm 9.7$ & 0.001 \\
\hline WHR & $0.96 \pm 0.06$ & $0.94 \pm 0.07$ & 0.01 & $0.96 \pm 0.07$ & $0.92 \pm 0.07$ & 0.01 \\
\hline
\end{tabular}

${ }^{a} \mathrm{P}$ values test the hypothesis of no differences in the studied parameters between baseline and month 3.

Table 3. Comparison of body composition (DXA) parameters before and after the intervention in groups A and B

\begin{tabular}{|c|c|c|c|c|c|c|}
\hline Variables & $\begin{array}{l}\text { Group A before } \\
\text { intervention } \\
(\mathrm{n}=21)\end{array}$ & $\begin{array}{l}\text { Group A after } \\
\text { intervention } \\
(n=21)\end{array}$ & $\mathrm{p}$ value $\mathrm{a}^{\mathrm{a}}$ & $\begin{array}{l}\text { Group B before } \\
\text { intervention } \\
(\mathrm{n}=17)\end{array}$ & $\begin{array}{l}\text { Group B after } \\
\text { intervention } \\
(\mathrm{n}=17)\end{array}$ & $\mathrm{p}$ value $\mathrm{a}^{\mathrm{a}}$ \\
\hline Total body fat, \%fat & $47.5 \pm 4.0$ & $45.5 \pm 3.7$ & $<0.001$ & $46.9 \pm 3.7$ & $44.9 \pm 3.7$ & $<0.001$ \\
\hline Total body fat mass, $\mathrm{g}$ & $41,954.6 \pm 7,602.7$ & $39,218.6 \pm 7,258.0$ & $<0.001$ & $42,692.8 \pm 8,615.0$ & $40,024.9 \pm 8,442.5$ & $<0.001$ \\
\hline Total body lean mass, $\mathrm{g}$ & $45,969.0 \pm 5,468.3$ & $46,597.9 \pm 5,961.1$ & NS & $47,843.9 \pm 6,280.4$ & $48,640.1 \pm 6,390.6$ & $<0.001$ \\
\hline Total body fat-free mass, $g$ & $48,709.4 \pm 5,589.2$ & $49,287.8 \pm 6,090.4$ & NS & $50,773.7 \pm 6,482.9$ & $51,537.1 \pm 6,580.7$ & $<0.001$ \\
\hline
\end{tabular}

NS = Not significant.

${ }^{a} \mathrm{P}$ values test the hypothesis of no differences in studied parameters between baseline and month 3 .

Table 4. Comparison of physical capacity (GXT) parameters before and after the intervention in groups A and B

\begin{tabular}{|c|c|c|c|c|c|c|}
\hline Variables & $\begin{array}{l}\text { Group A before } \\
\text { intervention } \\
(\mathrm{n}=21)\end{array}$ & $\begin{array}{l}\text { Group A after } \\
\text { intervention } \\
(\mathrm{n}=21)\end{array}$ & $\mathrm{p}$ value $^{\mathrm{a}}$ & $\begin{array}{l}\text { Group B before } \\
\text { intervention } \\
(\mathrm{n}=17)\end{array}$ & $\begin{array}{l}\text { Group B after } \\
\text { intervention } \\
(n=17)\end{array}$ & $\mathrm{p}$ value \\
\hline $\mathrm{VO}_{2 \text { peak }}, \mathrm{ml} /(\mathrm{kg} \times \mathrm{min})$ & $17.3 \pm 2.1$ & $20.4 \pm 3.3$ & $<0.001$ & $18.3 \pm 3.3$ & $22.1 \pm 4.6$ & $<0.001$ \\
\hline $\mathrm{WR}_{\max }, \mathrm{W}$ & $104.8 \pm 17.0$ & $131.0 \pm 26.1$ & $<0.001$ & $113.2 \pm 23.6$ & $142.6 \pm 21.2$ & $<0.001$ \\
\hline TTE, s & $470.2 \pm 86.2$ & $575.5 \pm 114.6$ & $<0.001$ & $524.4 \pm 104.7$ & $653.8 \pm 124.9$ & $<0.001$ \\
\hline $\mathrm{WR}_{\mathrm{VT}}, \mathrm{W}$ & $78.8 \pm 14.7$ & $97.5 \pm 19.7$ & $<0.001$ & $89.1 \pm 18.2$ & $112.5 \pm 20.4$ & $<0.001$ \\
\hline $\mathrm{HR}_{\mathrm{VT}}, \mathrm{BPM}$ & $130.3 \pm 14.5$ & $132.7 \pm 16.9$ & NS & $137.3 \pm 16.3$ & $138.5 \pm 12.6$ & NS \\
\hline
\end{tabular}

NS = Not significant.

a $\mathrm{P}$ values test the hypothesis of no differences in studied parameters between baseline and month 3 .

Table 5. Comparison of circulatory system parameters before and after the intervention in groups A and B

\begin{tabular}{|c|c|c|c|c|c|c|}
\hline Variables & $\begin{array}{l}\text { Group A before } \\
\text { intervention } \\
(n=21)\end{array}$ & $\begin{array}{l}\text { Group A after } \\
\text { intervention } \\
(n=21)\end{array}$ & $\mathrm{p}$ value $\mathrm{a}^{\mathrm{a}}$ & $\begin{array}{l}\text { Group B before } \\
\text { intervention } \\
(\mathrm{n}=17)\end{array}$ & $\begin{array}{l}\text { Group B after } \\
\text { intervention } \\
(\mathrm{n}=17)\end{array}$ & $p$ value $^{a}$ \\
\hline Resting HR, bpm & $79.7 \pm 14.1$ & $72.2 \pm 7.9$ & 0.007 & $75.2 \pm 8.1$ & $71.8 \pm 5.3$ & 0.033 \\
\hline Exercise HR, bpm & $146.0 \pm 18.0$ & $147.4 \pm 21.3$ & NS & $154.6 \pm 23.3$ & $155.6 \pm 19.7$ & NS \\
\hline Resting SBP, mm Hg & $138.1 \pm 11.9$ & $131.4 \pm 12.8$ & 0.002 & $141.4 \pm 18.4$ & $132.5 \pm 14.3$ & 0.003 \\
\hline Resting DBP, mm Hg & $83.2 \pm 10.9$ & $77.7 \pm 8.8$ & 0.003 & $84.8 \pm 11.6$ & $80.8 \pm 9.9$ & 0.018 \\
\hline Exercise SBP, mm Hg & $169.3 \pm 31.6$ & $176.7 \pm 30.8$ & NS & $182.4 \pm 25.3$ & $179.0 \pm 24.5$ & NS \\
\hline Exercise DBP, mm Hg & $101.1 \pm 27.0$ & $72.0 \pm 23.3$ & 0.001 & $91.5 \pm 17.0$ & $75.0 \pm 17.3$ & $<0.001$ \\
\hline
\end{tabular}

NS = Not significant.

${ }^{a} \mathrm{P}$ values test the hypothesis of no differences in studied parameters between baseline and month 3 . 
Table 6. Comparison of change in studied parameters from baseline to the 3-month point of the intervention in groups $\mathrm{A}$ and $\mathrm{B}$

\begin{tabular}{|c|c|c|c|}
\hline Variables & Group A $(\mathrm{n}=21)$ & Group B (n = 17) & $\mathrm{p}$ value \\
\hline$\Delta$ body mass, kg & $-2.20 \pm 2.12$ & $-2.71 \pm 2.25$ & NS \\
\hline$\Delta \mathrm{BMI}, \mathrm{kg} / \mathrm{m}^{2}$ & $-0.84 \pm 0.80$ & $-0.99 \pm 0.80$ & NS \\
\hline$\Delta$ waist circumference, $\mathrm{cm}$ & $-5.26 \pm 4.45$ & $-7.65 \pm 4.56$ & NS \\
\hline$\Delta$ hip circumference, $\mathrm{cm}$ & $-3.33 \pm 2.83$ & $-3.41 \pm 3.58$ & NS \\
\hline$\Delta \mathrm{WHR}$ & $-0.02 \pm 0.03$ & $-0.04 \pm 0.05$ & NS \\
\hline$\Delta$ total body fat, $\%$ fat & $-2.00 \pm 1.11$ & $-2.05 \pm 1.23$ & NS \\
\hline$\Delta$ total body fat mass, $\mathrm{g}$ & $-2,735.95 \pm 1,703.59$ & $-2,667.88 \pm 1,885.40$ & NS \\
\hline$\Delta$ total body lean mass, $g$ & $628.86 \pm 1,720.78$ & $796.12 \pm 757.95$ & NS \\
\hline$\Delta$ total body fat-free mass, $g$ & $578.38 \pm 1,661.16$ & $763.41 \pm 729.28$ & NS \\
\hline$\Delta \mathrm{VO}_{2 \text { peak }}, \mathrm{ml} /(\mathrm{kg} \times \min )$ & $3.03 \pm 2.45$ & $3.82 \pm 2.05$ & NS \\
\hline$\Delta \mathrm{WR}_{\max }, \mathrm{W}$ & $26.2 \pm 19.0$ & $29.4 \pm 13.2$ & NS \\
\hline$\Delta \mathrm{TTE}, \mathrm{s}$ & $104.5 \pm 67.9$ & $129.4 \pm 54.0$ & NS \\
\hline$\Delta \mathrm{WR}_{\mathrm{VT}, \mathrm{W}}$ & $19.7 \pm 15.8$ & $23.4 \pm 6.2$ & NS \\
\hline$\Delta \mathrm{HR}_{\mathrm{VT}}, \mathrm{bpm}$ & $2.4 \pm 10.2$ & $1.2 \pm 10.2$ & NS \\
\hline$\Delta$ resting $\mathrm{HR}, \mathrm{bpm}$ & $-7.43 \pm 11.32$ & $-3.41 \pm 6.04$ & NS \\
\hline$\Delta$ exercise $\mathrm{HR}$, bpm & $1.43 \pm 9.68$ & $0.94 \pm 7.7 .64$ & NS \\
\hline$\Delta$ resting $\mathrm{SBP}, \mathrm{mm} \mathrm{Hg}$ & $-6.76 \pm 8.91$ & $-8.88 \pm 10.50$ & NS \\
\hline$\Delta$ resting $\mathrm{DBP}, \mathrm{mm} \mathrm{Hg}$ & $-5.48 \pm 7.52$ & $-3.94 \pm 6.19$ & NS \\
\hline$\Delta$ exercise SBP, mm Hg & $7.38 \pm 22.33$ & $-3.35 \pm 24.62$ & NS \\
\hline$\Delta$ exercise $\mathrm{DBP}, \mathrm{mm} \mathrm{Hg}$ & $-29.10 \pm 35.05$ & $-16.47 \pm 15.67$ & NS \\
\hline
\end{tabular}

NS = Not significant

Both the endurance training and the endurance strength training led to significant decreases in resting HR, resting SBP, resting DBP, and exercise DBP. A nonsignificant tendency towards an increase in exercise HR was observed in both groups. Compared with the baseline measurements, a tendency of exercise SBP to increase in group A and to decrease in group B was recorded. The comparison of circulatory system parameters before and after the intervention is presented in table 5 .

To evaluate the differences between endurance training and endurance strength training, we compared the 3-month value of each parameter with the baseline value. No significant differences were detected between the two groups for any of the studied parameters (table 6).

\section{Discussion}

Our findings show that both endurance and endurance strength training exert similar positive effects on anthropometric parameters, body composition, physical capacity, and circulatory parameters in women with abdominal obesity. This study demonstrated that key benefits could be achieved in healthy obese women after as little as 3 months of a training program.

Both types of applied exercise positively modified the anthropometric parameters of our study groups. We observed decreases in body mass (and thus BMI) as well as in waist and hip circumference. The decrease in waist circumference is especially important, as this parameter is considered to be an independent factor of cardiovascular risk [24]. The results of our trial are compatible with those of the research performed by Willis et al. [25] on obese men and women, which showed that mixed endurance strength training lead to a greater decrease in waist circumference than endurance training alone. Although the average 
Skrypnik et al.: Effects of Endurance and Endurance Strength Training on Body Composition and Physical Capacity in Women with Abdominal Obesity

decrease in waist circumference noted in our study was $2 \mathrm{~cm}$ greater in group B than in group A, this difference was statistically insignificant. Recent study conducted by Sanal et al. [23] on an obese population showed that mixed endurance strength training reduced the percentage of fat on the trunk in men, while decreases in fat mass on the legs were observed in the female group. On the other hand, no such relative advantage of mixed endurance strength training in weight control has been documented in the sedentary, nondiabetic, overweight, middle aged subjects considered in Studies of a Targeted Risk Reduction Intervention through Defined Exercise (STRRIDE) [26] or in the trial performed by Davidson et al. [27] on abdominally obese older men and women. Noticeably, compared to our 3-month training program, the duration of the training plans applied in these two studies was 8 months and 6 months, respectively. Thus, the effect of longer-term training may be observed in those trials. In our study, we decided (like others [23, 28-30]) to focus on a shorter 3 -month training program. Recently, the valuable effects of the two types of training in obese patients following 2 months of physical activity program were documented by Ghroubi et al. [31].

Our results reveal that endurance and endurance strength training favorably affects body composition by decreasing the total body fat and TBFat. This effect of the exercise is crucial to the treatment of obesity. Mixed endurance strength training, in contrast to endurance training, led to statistically significant increases in TBLean and total body fat-free mass. However, the differences between endurance and endurance strength training do not reach statistical significance in the case of any of the examined body composition parameters. Our findings are in contrast to earlier studies of Marzolini et al. [25] and Willis et al. [32], in which mixed endurance strength exercise was found to be more beneficial than endurance exercise with respect to total body fat percentage, TBLean, and total body fat-free mass. It is noteworthy that Marzolini et al. [25] performed their study on individuals with coronary artery disease - a condition which served as exclusion criterion in our study. Also, in contrast to the 3 -month training program applied in our study, 8 months of physical activity were performed in the study of Willis et al. [32].

Our results indicate that both types of exercise beneficially influence physical capacity as shown by a significant increase in $\mathrm{VO}_{2 \text { peak, }}$ WRmax, TTE, and $\mathrm{WR}_{\mathrm{VT}}$. These parameters are widely approved predictors of cardiologic, pulmonological, and metabolic risk. Many studies showed that obesity unfavorably affects exercise capacity [33, 34] by reducing cardiorespiratory fitness compared to matched controls [33, 35, 36]. Also in our study, both groups of participants had low values of $\mathrm{VO}_{2 \text { peak }}$ at baseline. Our training interventions (both endurance and mixed endurance strength training) caused statistically significant increases in cardiorespiratory fitness and exercise capacity, which confirms the observations of others [36, 37]. However, despite the tendency toward a slightly higher increase in $\mathrm{VO}_{2 \text { peak, }}$ WRmax, TTE, and $\mathrm{WR}_{\mathrm{VT}}$ observed in group $\mathrm{B}$, we did not show any statistically significant predominance of one particular type of training for physical capacity improvement. The nonsignificant tendency may be caused, on the one hand, by muscle strength improvement and, on the other, by the statistically significant increase in TBLean and total body fat-free mass noted after mixed endurance strength training [20, 38]. It has been recently reported that, compared to overweight women, overweight women with DM2 developed greater maximal oxygen uptake after 3 months of endurance training [39]. In our study, DM2 was among the exclusion criteria. In other trials on obese individuals (with a predominance of women in the studied groups), the physical capacity parameters increased significantly in the high-intensity aerobic training group when compared with the strength-trained group [30].

In our study, endurance and endurance strength training positively affected circulatory parameters, as shown by the decrease in resting HR, resting SBP and DBP, and exercise DBP. 
Skrypnik et al.: Effects of Endurance and Endurance Strength Training on Body

These parameters are generally accepted and applied markers of cardiovascular risk. We did not find any statistically significant superiority of the investigated types of exercise for any circulatory parameters during the study. Nevertheless, the published data concerning the precise influence of endurance and endurance strength training type on circulatory parameters level remains unclear and differs by studied populations. Recently, Lucotti et al. [40] demonstrated a greater decrease in resting SBP in the case of endurance training and an increase in resting DBP in the case of endurance strength training in obese diabetic patients on a diet. Berent et al. [41] recorded a decrease in resting DBP, resting SBP, and resting HR as an effect of combined endurance strength training in patients with cardiovascular disease. Similar results concerning mixed endurance strength training in relation to resting SBP and resting DBP were obtained in elderly hypertensive patients by De Moraes et al. [42]. The influence of endurance training on cardiovascular parameters in postmenopausal elderly women also included a significant decrease in resting SBP and resting DBP [29, 43-45]. Furthermore, an increase in maximal HR after 36 weeks of training [45], or no significant change in resting HR after 12 weeks of training [43], were reported by some authors. On the contrary, no significant changes in resting SBP and resting DBP has been seen following 6 months of training in a group of postmenopausal women [46]. Other studies have demonstrated a reduction in resting SBP and resting DBP after 12 weeks of regular endurance training in postmenopausal women with mildly elevated BP [47]. The significantly decreased resting SBP, DBP, and HR observed in our study may therefore be a consequence of the 3-month exercise program performed in the study, which allows us to estimate only the short-term effect of the training. In their exploration of mixed endurance strength training in obese middle-aged women, Seo et al. [29] observed a decrease in resting DBP and, unlike us, no significant tendency to decrease resting SBP. Thus, the number of analyzed women in their subgroup may (as in our case) constitute a limitation of that study [29]. Conversely, our results are in line with results of Kargarfard et al. [48], who registered decreases in resting HR, resting SBP, resting DBP, and exercise DBP, and an increase in exercise HR after endurance training in patients who had suffered myocardial infarctions. The effect of endurance and strength training on circulatory parameters in obese sedentary women has been explored in the study of Chaudhary et al. [49], who found that exercise HR decreased after strength training and increased after endurance training and was accompanied by significant SBP and DBP changes following physical activity [49]. The study of Schjerve et al. [30] compared the effects of strength training and endurance training of moderate and high intensity on circulatory parameters in obese adults. A lack of change in the SBP of all groups, a decrease in DBP in the endurance groups, and a lack of change in DBP in the strength group were found in the study. To draw a conclusion, Cardoso et al. [50] reviewed available studies regarding comparisons of the impact of endurance and strength training on blood parameters and showed that there is undoubtedly a decreasing effect of endurance training on blood pressure. Nevertheless, the decreasing effect of strength exercise on SBP and DBP was considered uncertain in that study, and this issue requires deeper investigation.

\section{Study Limitations}

The major limitation of this study is the relatively small number of subjects completing the intervention. The main reasons for this were the very rigorous inclusion and exclusion criteria. Conversely, such criteria enabled us to select a homogenous group of subjects not encumbered by diseases or states that might significantly affect the results of the study. 
Skrypnik et al.: Effects of Endurance and Endurance Strength Training on Body Composition and Physical Capacity in Women with Abdominal Obesity

\section{Study Strong Points}

It is worth emphasizing that the subjects' compliance ratio was over 85\%. Participation in training was also very high, which strongly enhances the credibility of the study. A large variety of parameters were measured and compared in the same study group. The inclusion and exclusion criteria were very strict, eliminating the influence of disrupting factors. The greatest strength of the study is its comparative character, which allowed a clear result regarding the superiority of one of the forms of training to be drawn. This approach was present only in few previous studies.

\section{Conclusions}

Our findings demonstrate strong evidence for a favorable effect of 3 months of endurance and endurance strength training on anthropometric parameters, body composition, physical capacity, and circulatory system function in women with abdominal obesity. The observed benefits were comparable for both types of exercise, and further studies on a large scale and with long-term follow up should be considered to draw a precise conclusion.

\section{Acknowledgements}

All authors conceived and carried out experiments and analyzed data. All authors were involved in writing the paper and had final approval of the submitted and published versions. Competing interests: the authors have no competing interests.

\section{Disclosure Statement}

Authors indicate no conflicts of interest.

\section{References}

1 World Health Organization: Obesity: Preventing and Managing the Global Epidemic, WHO Technical Report Series number 894. Geneva, WHO, 2000.

-2 Finucane MM, Stevens GA, Cowan MJ, Danaei G, Lin JK, Paciorek CJ, Singh GM, Gutierrez HR, Lu Y, Bahalim AN, Farzadfar F, Riley LM, Ezzati M; Global Burden of Metabolic Risk Factors of Chronic Diseases Collaborating Group (Body Mass Index): National, regional, and global trends in body-mass index since 1980: systematic analysis of health examination surveys and epidemiological studies with 960 country-years and 9.1 million participants. Lancet 2011;377:557-567.

-3 St-Onge MP, Heymsfield SB: Overweight and obesity status are linked to lower life expectancy. Nutr Rev 2003; 61:313-316.

4 Walls HL, Backholer K, Proietto J, McNeil JJ: Obesity and trends in life expectancy. J Obes 2012;2012:107989.

5 Nguyen DM, El-Serag HB: The epidemiology of obesity. Gastroenterol Clin North Am 2010;39:1-7.

6 Finkelstein EA, Trogdon JG, Cohen JW, Dietz W: Annual medical spending attributable to obesity: payer-and service-specific estimates. Health Aff 2009;28:w822-w831.

7 Klein S, Burke LE, Bray GA, Blair S, Allison DB, Pi-Sunyer X, Hong Y, Eckel RH: Clinical implications of obesity with specific focus on cardiovascular disease: a statement for professionals from the American Heart Association Council on Nutrition, Physical Activity, and Metabolism: Endorsed by the American College of Cardiology Foundation. Circulation 2004;110:2952-2967.

-8 Wing RR, Lang W, Wadden TA, Safford M, Knowler WC, Bertoni AG, Hill JO, Brancati FL, Peters A, Wagenknecht L: Benefits of modest weight loss in improving cardiovascular risk factors in overweight and obese individuals with type 2 diabetes. Diabetes Care 2011;34:1481-1486.

-9 Haskell WL, Lee IM, Pate RR, Powell KE, Blair SN, Franklin BA, Macera CA, Heath GW, Thompson PD, Bauman A: Physical activity and public health: updated recommendation for adults from the American College of Sports Medicine and the American Heart Association. Med Sci Sports Exerc 2007;39:1423-1434. 


\begin{tabular}{l|l}
\hline Obes Facts 2015;8:175-187 \\
\hline DOI: $10.1159 / 000431002$ & $\begin{array}{l}\text { C) 2015 S. Karger GmbH, Freiburg } \\
\text { www.karger.com/ofa }\end{array}$ \\
\hline
\end{tabular}

Skrypnik et al.: Effects of Endurance and Endurance Strength Training on Body

Composition and Physical Capacity in Women with Abdominal Obesity

10 Swift DL, Lavie CJ, Johannsen NM, Arena R, Earnest CP, O’Keefe JH, Milani RV, Blair SN, Church TS: Physical activity, cardiorespiratory fitness, and exercise training in primary and secondary coronary prevention. Circ J 2013;77:281-292.

11 Donnelly JE, Blair SN, Jakicic JM, Manore MM, Rankin JW, Smith BK: Appropriate physical activity intervention strategies for weight loss and prevention of weight regain for adults. Med Sci Sports Exerc 2009;41:459-471.

-12 Church TS, Blair SN, Cocreham S, Johannsen N, Johnson W, Kramer K, Mikus CR, Myers V, Nauta M, Rodarte RQ, Sparks L, Thompson A, Earnest CP: Effects of aerobic and resistance training on hemoglobin a1c levels in patients with type 2 diabetes. JAMA 2010;304:2253-2262.

13 Swift DL, Earnest CP, Blair SN, Church TS: The effect of different doses of aerobic exercise training on endothelial function in postmenopausal women with elevated blood pressure: results from the DREW study. Br J Sports Med 2012;46:753-758.

14 Johannsen NM, Swift DL, Lavie CJ, Earnest CP, Blair SN, Church TS: Categorical analysis of the impact of aerobic and resistance exercise training, alone and in combination, on cardiorespiratory fitness levels in patients with type 2 diabetes mellitus: results from the HART-D study. Diabetes Care 2013;36:3305-3312.

15 Kraus WE, Houmard JA, Duscha BD, Knetzger KJ, Wharton MB, McCartney JS, Bales CW, Henes S, Samsa GP, Otvos JD, Kulkarni KR, Slentz CA: Effects of the amount and intensity of exercise on plasma lipoproteins. N Engl J Med 2002;347:1483-1492.

16 Kodama S, Tanaka S, Saito K, Shu M, Sone Y, Onitake F, Suzuki E, Shimano H, Yamamoto S, Kondo K, Ohashi Y, Yamada N, Sone H: Effect of aerobic exercise training on serum levels of high-density lipoprotein cholesterol: a meta-analysis. Arch Intern Med 2007;167:999-1008.

17 Myers VH, McVay MA, Brashear MM, Johannsen NM, Swift DL, Kramer K, Harris MN, Johnson WD, Earnest CP, Church TS: Exercise training and quality of life in individuals with type 2 diabetes: a randomized controlled trial. Diabetes Care 2013;36:1884-1890.

18 Jakicic JM: Exercise in the treatment of obesity. Endocrinol Metab Clin North Am 2003;32:967-980.

19 Tsigos C, Hainer V, Basdevant A, Finer N, Fried M, Mathus-Vliegen E, Micic D, Maislos M, Roman G, Schutz Y, Toplak H, Zahorska-Markiewicz B: Management of obesity in adults: European clinical practice guidelines. Obes Facts 2008;1:106-116.

20 Winett RA, Carpinelli RN: Potential health-related benefits of resistance training. Prev Med 2001;33:503-513.

-21 Mancia G, Fagard R, Narkiewicz K, Redón J, Zanchetti A, Böhm M, Christiaens T, Cifkova R, De Backer G, Dominiczak A, Galderisi M, Grobbee DE, Jaarsma T, Kirchhof P, Kjeldsen SE, Laurent S, Manolis AJ, Nilsson PM, Ruilope LM, Schmieder RE, Sirnes PA, Sleight P, Viigimaa M, Waeber B, Zannad F; Task Force Members: 2013 ESH/ESC guidelines for the management of arterial hypertension. The Task Force for the Management of Arterial Hypertension of the European Society of Hypertension (ESH) and of the European Society of Cardiology (ESC). J Hypertens 2013;31:1281-1357.

-22 Lebeck J, Østergård T, Rojek A, Füchtbauer EM, Lund S, Nielsen S, Praetorius J: Gender-specific effect of physical training on AQP7 protein expression in human adipose tissue. Acta Diabetol 2012;49(suppl 1):S215-S226.

23 Sanal E, Ardic F, Kirac S: Effects of aerobic or combined aerobic resistance exercise on body composition in overweight and obese adults: gender differences. A randomized intervention study. Eur J Phys Rehabil Med 2013;49:1-11.

24 Janssen I, Katzmarzyk PT, Ross R: Waist circumference and not body mass index explains obesity-related health risk. Am J Clin Nutr 2004;79:379-384.

25 Willis LH, Slentz CA, Bateman LA, Shields AT, Piner LW, Bales CW, Houmard JA, Kraus WE: Effects of aerobic and/or resistance training on body mass and fat mass in overweight or obese adults. J Appl Physiol 2012;113: 1831-1837.

26 Bateman LA, Slentz CA, Willis LH, Shields AT, Piner LW, Bales CW, Houmard JA, Kraus WE: Comparison of aerobic versus resistance exercise training effects on metabolic syndrome (from the Studies of a Targeted Risk Reduction Intervention through Defined Exercise - STRRIDE-AT/RT). Am J Cardiol 2011;108:838-844.

-27 Davidson LE, Hudson R, Kilpatrick K, Kuk JL, McMillan K, Janiszewski PM, Lee S, Lam M, Ross R: Effects of exercise modality on insulin resistance and functional limitation in older adults: a randomized controlled trial. Arch Intern Med 2009;169:122-131.

28 Saremi A, Shavandi N, Parastesh M, Daneshmand H: Twelve-week aerobic training decreases chemerin level and improves cardiometabolic risk factors in overweight and obese men. Asian J Sports Med 2010;1:151-158.

-29 Seo DI, So WY, Ha S, Yoo EJ, Kim D, Singh H, Fahs CA, Rossow L, Bemben DA, Bemben MG, Kim E: Effects of 12 weeks of combined exercise training on visfatin and metabolic syndrome factors in obese middle-aged women. J Sports Sci Med 2011;10:222-226.

-30 Schjerve IE, Tyldum GA, Tjønna AE, Stølen T, Loennechen JP, Hansen HE, Haram PM, Heinrich G, Bye A, Najjar SM, Smith GL, Slørdahl SA, Kemi OJ, Wisløff U: Both aerobic endurance and strength training programmes improve cardiovascular health in obese adults. Clin Sci 2008;115:283-293.

-31 Ghroubi S, Elleuch H, Chikh T, Kaffel N, Abid M, Elleuch MH: Physical training combined with dietary measures in the treatment of adult obesity. A comparison of two protocols. Ann Phys Rehabil Med 2009;52:394-413.

-32 Marzolini S, Oh PI, Brooks D: Effect of combined aerobic and resistance training versus aerobic training alone in individuals with coronary artery disease: a meta-analysis. Eur J Prevent Cardiol 2012;19:81-94.

-33 Hulens M, Vansant G, Lysens R, Claessens AL, Muls E: Exercise capacity in lean versus obese women. Scand J Med Sci Sports 2001;11:305-309. 
Skrypnik et al.: Effects of Endurance and Endurance Strength Training on Body Composition and Physical Capacity in Women with Abdominal Obesity

-34 Lavie CJ, Milani RV: Effects of cardiac rehabilitation, exercise training, and weight reduction on exercise capacity, coronary risk factors, behavioral characteristics, and quality of life in obese coronary patients. Am J Cardiol 1997;79:397-401.

-35 Meyers DA, Goldberg AP, Bleecker ML, Coon PJ, Drinkwater DT, Bleecker ER: Relationship of obesity and physical fitness to cardiopulmonary and metabolic function in healthy older men. J Gerontol 1991;46:57-65.

-36 Jorge ML, de Oliveira VN, Resende NM, Paraiso LF, Calixto A, Diniz AL, Resende ES, Ropelle ER, Carvalheira JB, Espindola FS, Jorge PT, Geloneze B: The effects of aerobic, resistance, and combined exercise on metabolic control, inflammatory markers, adipocytokines, and muscle insulin signaling in patients with type 2 diabetes mellitus. Metabolism 2011;60:1244-1252.

37 Park SK, Park JH, Kwon YC, Kim HS, Yoon MS, Park HT: The effect of combined aerobic and resistance exercise training on abdominal fat in obese middle-aged women. J Physiol Anthropol Appl Human Sci 2003;22:129_ 135.

38 Maiorana A, O’Driscoll G, Cheetham C, Collis J, Goodman C, Rankin S, Taylor R, Green D: Combined aerobic and resistance exercise training improves functional capacity and strength in CHF. J Appl Physiol 2000;88:15651570.

39 Brandenburg SL, Reusch JE, Bauer TA, Jeffers BW, Hiatt WR, Regensteiner JG: Effects of exercise training on oxygen uptake kinetic responses in women with type 2 diabetes. Diabetes Care 1999;22:1640-1646.

40 Lucotti P, Monti LD, Setola E, Galluccio E, Gatti R, Bosi E, Piatti P: Aerobic and resistance training effects compared to aerobic training alone in obese type 2 diabetic patients on diet treatment. Diabetes Res Clin Pract 2011;94:395-403.

41 Berent R, von Duvillard SP, Crouse SF, Sinzinger H, Green JS, Schmid P: Resistance training dose response in combined endurance-resistance training in patients with cardiovascular disease: a randomized trial. Arch Phys Med Rehabil 2011;92:1527-1533.

42 Moraes WM, Souza PR, Pinheiro MH, Irigoyen MC, Medeiros A, Koike MK: Exercise training program based on minimum weekly frequencies: effects on blood pressure and physical fitness in elderly hypertensive patients. Rev Bras Fisioter 2012;16:114-121.

43 Braz NF, Carneiro MV, Oliveira-Ferreira F, Arrieiro AN, Amorim FT, Lima MM, Avelar NC, Lacerda AC, Peixoto MF: Influence of aerobic training on cardiovascular and metabolic parameters in elderly hypertensive women. Int J Prev Med 2012;3:652-659.

-44 Monteiro LZ, Fiani CR, Freitas MC, Zanetti ML, Foss MC: Decrease in blood pressure, body mass index and glycemia after aerobic training in elderly women with type 2 diabetes. Arq Bras Cardiol 2010;95:563-570.

45 Park SK, Park JH, Kwon YC, Yoon MS, Kim CS: The effect of long-term aerobic exercise on maximal oxygen consumption, left ventricular function and serum lipids in elderly women. J Physiol Anthropol 2003;22:11-17.

46 Swift DL, Johannsen NM, Tudor-Locke C, Earnest CP, Johnson WD, Blair SN, Sénéchal M, Church TS: Exercise training and habitual physical activity: a randomized controlled trial. Am J Prev Med 2012;43:629-635.

47 Seals DR, Silverman HG, Reiling MJ, Davy KP: Effect of regular aerobic exercise on elevated blood pressure in postmenopausal women. Am J Cardiol 1997;80:49-55.

48 Kargarfard M, Rouzbehani R, Basati F: Effects of exercise rehabilitation on blood pressure of patients after myocardial infarction. Int J Prev Med 2010;1:124-130.

49 Chaudhary S, Kang MK, Sandhu JS: The effects of aerobic versus resistance training on cardiovascular fitness in obese sedentary females. Asian J Sports Med 2010;1:177-184.

50 Cardoso CG Jr, Gomides RS, Queiroz AC, Pinto LG, da Silveira Lobo F, Tinucci, Mion D Jr, de Moraes Forjaz CL: Acute and chronic effects of aerobic and resistance exercise on ambulatory blood pressure. Clinics 2010;65: 317-325. 